\title{
COMPARATIVE ANALYSIS OF SIMULATION RESULTS OF HARD- TO-CUT MATERIALS MACHINING BY COATED CUTTING TOOLS
}

\author{
STUPNYTSKYY Vadym ${ }^{1 *}$, XIANNING She ${ }^{1}$ \\ ${ }^{1}$ Lviv Polytechnic National University, Department of Mechanical Engineering Technologies, Institute of \\ Engineering Mechanics and Transport, Profesorska 1, Lviv, Ukraine, e-mail: vadym.v.stupnytskyi@lpnu.ua
}

\begin{abstract}
The article describes the system approach to simulation the process of machining hard-to-cut materials using tools with wear-resistant coatings. In addition to increasing the wear resistance of the tool, factors such as thermal state model, load parameters and friction behavior at the tool-chip interface have been analyzed. A comparative analysis of these parameters is described in the article. It has been proven that the greatest wear of the cutting edge does not occur on the top of the tool, but in the area where the chip speed along the rake face of the cutting insert is greatest.
\end{abstract}

KEYWORDS: cutting simulation, wear-resistance coating, stress-strain state, chip thickness ratio

\section{Introduction}

One of the most important ways to improve a modern cutting tool is to increase tool life. The principle of increasing wear resistance of metal cutting tools due to additional treatment of surface layer of cutting edges forms the basis of modern improvement of cutting process. Increased tool life is mainly due to application of wear-resistant coatings and thermal treatment. Analysis of selection of structure and parameters of wear-resistant coatings is a current scientific technical and economic task. On the one hand, effective stress-strain state of cutting process must be ensured. On the other hand, increasing the cost of using expensive tools with wear-resistant coatings should be economically advantageous. This is especially important for CNC machines operating in the serial type of the manufacture production.

Studies of changes in cutting modes can be performed on the basis of prolonged and expensive experiments. However, stress-strain and thermal state analysis can be obtained by simulating different cutting processes for different materials using different wear resistant coatings. The advantage of this method is not only to save the cost and labor intensity of research, but a complex pattern of the of interconnected thermal, loading, deformation consequences of cutting in different modes can be obtained. An experienced researcher can draw very important conclusions: which of the alternative coatings can give the greatest required technological and economic effect.

\section{Literature review}

A number of negative factors arise during cutting of hard-to-treat materials $[1,2,3]$ :

- high temperature in a cutting zone which leads to a softening of tool's hard alloys. This contribute to reduce tool wear resistance and cutting speed, which adversely affects total machining productivity;

- high hardness and strength of poor machinability materials, which create great contact stresses in the cutting zone, increase the probability of brittle or plastic fracture of the cutting tool; 
- low thermal conductivity and high strength of hard-to-cut materials lead to increased intensity of heat flow towards the tool. This causes a reduction in tool life as a result of plastic destruction of the cutting blade;

- high chemical activity of most alloyed materials with the difficult machinability, especially at high cutting temperatures, leads to activation of physical and chemical processes on tool edges and it is the main reason for intensification of adhesion-fatigue and diffusion tool wear;

- tendency of hard-to-cut materials to be mechanically hardening during cutting results in increased intensity of abrasive wear.

Thus, it is a task to select most effective wear-resistant coating taking into account the specifics of cutting and the composition of the tool material. One of the most important indicators of the tool material in this case is the increased heat resistance, which is achieved due to the complex use of a hard alloy and a functional wear-resistant coating. Tool material with wear coating can be considered as composite material with optimal composition of surface (hardness, heat resistance, wear resistance) and volume (toughness, bending strength, compression) properties [4]. Really, on the one hand, the coating can significantly reduce the friction coefficient in the tool-workpiece system and reduce the power of friction heat sources. On the other hand, the coating having the shielding function is able to significantly reduce the intensity of heat flows into the cutting edge of the tool and thus increase the temperature threshold of the beginning of adhesion interaction in the "workpiece-tool" system and reduce the intensity of interdiffusion between them [4,5].

The scientific work [6] states that numerous material- and manufacturing-engineers have jointed their expertise, aiming at developing coatings meeting the needs for processing the most difficult-to-cut materials at the most extreme cutting conditions. The emerging of new workpiece, tool and film materials, the evolution of sophisticated coatings' characterization methods and the continuous need for higher productivity rates, maintain vivid the industrial and scientific interest for further advancing this field.

The set of tasks for selecting the structure and parameters of the wear-resistant tool coating should be solved depending on the machining conditions of the tool, the presumable material of the workpiece, technical and economic limitations. Many scientific papers $[4,5,6,7,8,9]$ are devoted to solving this problem. In general, the recommendations are based on experimental studies or on promotional proposals from the main producers of the cutting tool. However, the requirements of fast-realigned production, the need to treat a variety of materials, varying cutting parameters, and the high-quality requirements of the surface layer of machined surfaces require the use of simulation studies for cutting processes with different tool coatings. This can significantly reduce the time for engineering production preparation and optimize the selection of the best coating from a technological and economic point of view.

The machining mechanism is an extremely complex process, systematically studied for over a century. To increase the efficiency of the processing process, the tool material must be carefully selected, and the geometry of the edge must be precisely designed taking into account the optimization of cutting conditions $[5,6]$.

Usually, simulation modeling of cutting processes by tools with wear-resistant coatings is directed to research of thermal processes [5,7]. However, the stress-strain state of the machined surface layer, residual stresses and cutting loading parameters are equally important for deciding the effectiveness of the test coating.

Authors of scientific work [10] prove, that tool wear on the tool-chip and tool-workpiece interfaces (i.e. flank wear and crater wear) is strongly influenced by the cutting temperature, 
contact stresses, and relative sliding velocity at the interface. These process variables depend on tool and workpiece materials, tool geometry and coatings, cutting conditions, and use of coolant for the given application. Based on temperatures and stresses on the tool face predicted by the finite element analysis (FEA) simulation, tool wear may be estimated with acceptable accuracy using an empirical wear model.

Science work [6] indicates that coated tools wear mechanisms were explained by innovative methods for characterizing film material, functional and dimensional properties. These issues are supported by difficult-to-formalized computational procedures, which contribute in obtaining a thorough understanding of the tool wear mechanisms taking place during cutting with coated tools. The described procedures allow the prediction of coated tool cutting performance and the effective adaption of the cutting conditions to the film properties, thus restricting the related experimental cost. Appropriate substrate and coating thermal as well as mechanical treatments improving the tool wear behavior, were also introduced. The potential of applying coated cutting tools in difficult-to-cut materials was exhibited in characteristic workpiece material cases.

In work [11] numerical analysis of machining has been performed to study the impact of different coating layers on the machining process. Four cases were considered: an uncoated tool made of tungsten carbide (WC-Co) and coated tungsten carbides in three different configurations. The first one is made of one layer namely $\mathrm{TiN}$, the second one is composed of two layers $\left(\mathrm{Al}_{2} \mathrm{O}_{3}\right.$ and $\left.\mathrm{TiN}\right)$, and the last one has three layers $\left(\mathrm{TiCN}, \mathrm{Al}_{2} \mathrm{O}_{3}\right.$ and $\left.\mathrm{TiN}\right)$. The workpiece material was an AISI 316L stainless steel. All cutting conditions are fixed in order to highlight the effect of coatings independently from others influencing parameters. The analysis has shown the impact of the different configurations of coatings on the temperature level inside the tool and on its surface, on the pressure and also on the cutting loads.

A generalized analysis of literary sources $[4,6,9,10,12,13,14,15]$ concerning of the cutting process simulation using a wear-resistant coating tool makes it possible to draw the following conclusions:

1. The results of modeling of the power, thermal and stress-strain state of the workpiece and the tool with different coating of inserts will allow the calculated analysis of the quality of the machined surface layer and optimal cutting parameters taking into account the increased wear resistance of the cutting tool.

2. Optimal cutting parameters for coated tools increases the allowable cutting speed and productivity, because using of the coated cutting inserts reduce cutting temperature, cutting force and increase shear angle due to lower friction coefficient.

3. Use of wear-resistant tool coatings contributes to reduction of thermomechanical load on the cutting edge, prevention of appearance of tool material's local destruction, increase of crack resistance, which indicates necessity of modeling of cutting tool special design with optimized geometry of cutting edge.

4. The need for simulation analyses the friction behavior of the tool-chip interface under conditions that usually appear in metal cutting to effectively select the wear-resistant coating structure

5. The use of wear-resistant coatings is most advantageous for the machining of hard-to-cut materials with the high cutting speed. 


\section{FEM simulations of the cutting process}

Set of tasks for selection of structure and parameters of tool wear-resistant coatings shall be performed on the basis of machining conditions, base material of cutting tool, material of workpiece to be processed, geometry of cutting edge, assumed machining parameters. Coatings on the basis of the titan (such as nitride of titanium (TiN), carbide of titanium (TiC), carbonitride-titanium ( $\mathrm{TiCN})$ ) were widely adopted most for an intensification of processing of the hard-to-cut materials.

Plastic deformations in the chip forming zones are substantially dependent on shear fracture resistance [16]. Diffuse processes that affect the resistance of the machined layer are most actively implemented at this place. Namely, when local volumes of treated material are saturated in the plastic contact zone by alloying elements from tool's material, shear resistance will go up, which will necessarily lead to increase of the cutting forces. If the coating, along with the high heat resistance, is chemically inert to the material to be machined, it serves as an active barrier to inhibit diffusion of the atoms of the tool material into the chips. In this case, the shear resistance at the plastic contact portion is reduced. This results in reduced shear strength and cutting forces.

In order to investigate the effect of wear-resistant coatings on the formation of different physical states of the cutting process, a simulation study was carried out using the FEA system DEFORM 2D [17]. The advantage of this software product is the ability to solve complex nonlinear plastic deformation problems, while analytical solutions can be obtained only for cases of elastic deformation of structures under the influence of external loads. Among the advantages of using this software are [18]: improving tool and die design to reduce production and material costs; reduce the need for costly shop floor trials and redesign of tooling and processes; shorten lead time in bringing a new product to market etc. The source conditions for the DEFORM pre-processor during simulation of the machining (cutting) operation are: 2D or 3D model of machining part (surface); cutting parameters; 2D or a 3D model of the tool, geometry of the cutting edge, material and a covering; durability, mechanical, thermophysical characteristics of the processed material; model of tool's wear; remesh criteria (such as error of compliance of modeling on a power vector, vector of speed and admissible geometrical error; strain type (Lagrange Incremental or Steady-State machining); iteration method (Direct Iteration or Newton-Raphson), type of the deformation and temperature solver (Sparce or the Skyline method).

- The initial data for given study are: structure and parameters of machining process operation (in given case, it is hard turning)

- material of the workpiece and its geometric characteristics;

- structural-phase and thermodynamic state of machined surfaces;

- geometric parameters of the metal-cutting tool, material of its cutting edge,

- type and depth of insert's coating (Fig. 1);

- type of the tool wear forecasting model (Usui, Taylors's or Takeyama model [19]).

The wear-resistant tool coating subsystem is used in the Deform-2D/3D software in interactive mode. The system offers to select the most popular types of coating (including multilayer) from the library and to determine their depth in the base tool material of the cutting insert (Fig. 1) 

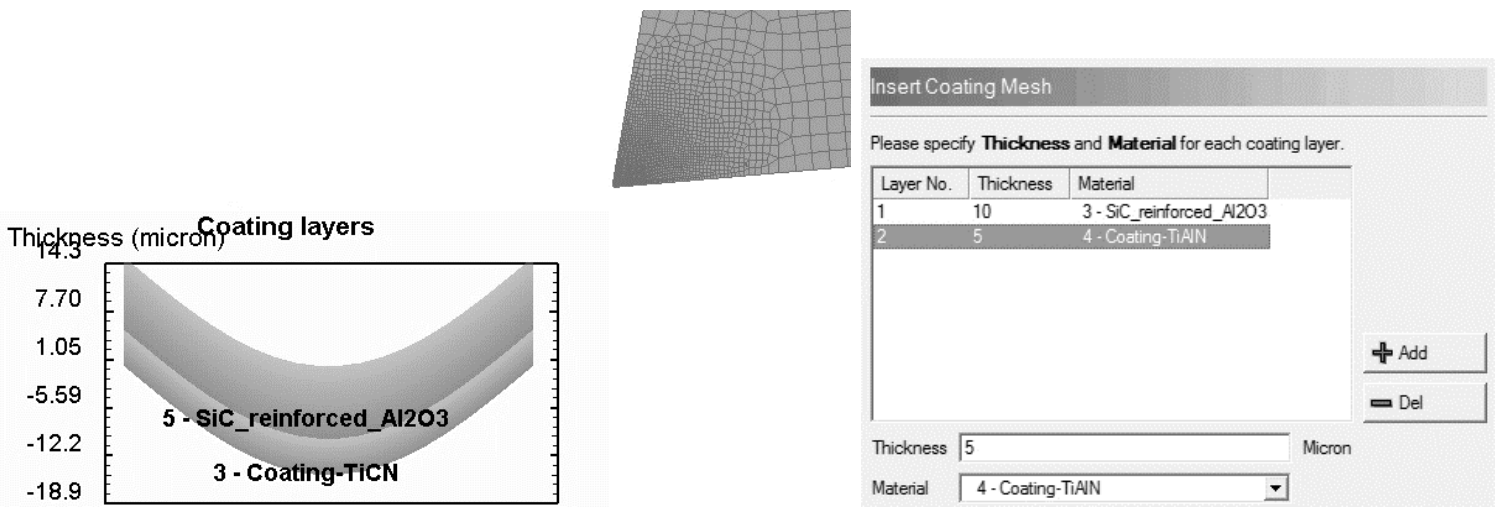

Fig. 1. Dialog box for assigning of the initial data on wear-resistant multi-layer tool coating in Deform-2D

In order to perform the main task of establishing characteristics of stress-strain and thermal state of surfaces formed during their mechanical treatment and their relations with parameters of wear-resistant coatings applied on metal-cutting tool, it is necessary to carry out a series of cutting process simulations, including studies both without applied tool coating, and studies with different wear-resistant coatings. In order to carry out such a series of experiments, it is necessary to create a basic simulation model on the basis of which the parameters of the best wear-resistant coating of the tool for the given cutting parameters will be set.

\section{Results and discussion.}

Analysis of the multi-step results of the dynamic simulation study was based on the obtained data after modeling the machining process for different cutting parameters, both for the tools without wear-resistant coating and separately for each type of tool coating under study. In addition, if no separate calculation is required to obtain graphical and analytical results of the stress-strain and thermodynamic state of the workpiece and the tool during machining, that the data array was changed in accordance with the geometric parameters of the metal cutting tool to determine the chip thickness ratio.

The machining process of alloyed stainless steel AISI4340 been simulated in DEFORM 2D in given study because the greatest effect of the use of wear-resistant tool coatings occurs during the treatment of hard-to-cut materials. AISI 4340 alloy steel is a low alloy steel containing chromium, nickel and molybdenum. This steel is mainly used in power transmission gears and shafts, aircraft landing gear, and other structural parts. Cutting parameters used: cutting speed is $120 \mathrm{~m} / \mathrm{min}$; feed rate is $0.25 \mathrm{~mm}$ per revolution; cutting depth is $1.5 \mathrm{~mm}$.

\subsection{Dependence of cutting thermal state on tool coating type}

Based on the study carried out in DEFORM 2D, there were obtained graphical relations of temperature arising from the cutting zone according to the use of different types of wearresistant coating of the of the metal cutting tool's insert or its absence. Analyzing the resulting relationships (Fig.2), it is obvious that this graph is divided into 2 conditional parts: Part of unstable cutting process (when the tool is rapidly heated) - from 0 to $0.003 \mathrm{~s}$ and part of stable machining in time - from 0.003 to the end of simulation studies (when the thermal state of the tool reaches a constant value and practically does not change). 


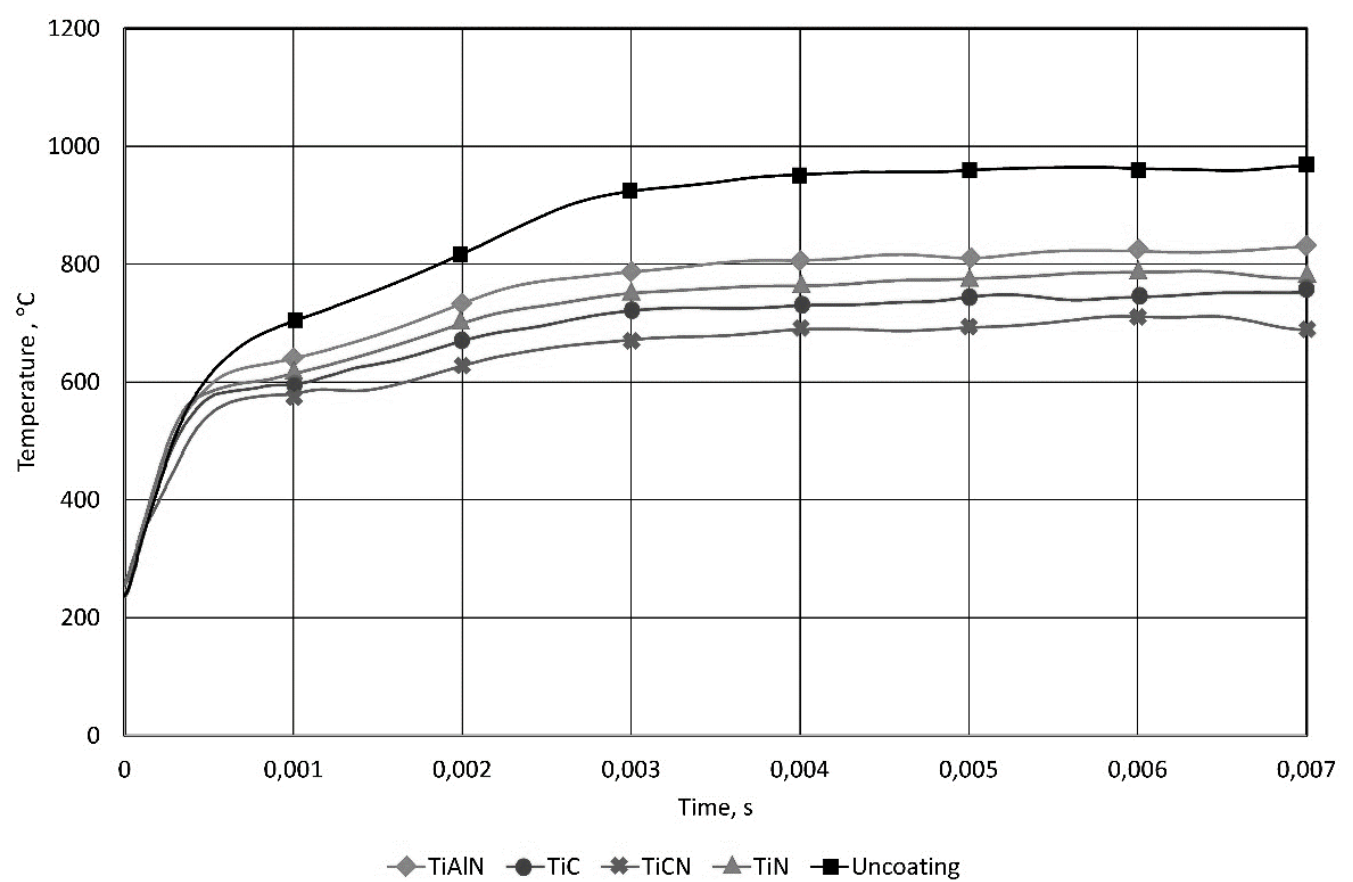

Fig. 2. Dependence of cutting temperature on tool coating type resulting from the simulation in Deform 2D

According to the graph (Fig.2), it can be concluded that the dynamics of temperature increase during the unstable cutting process is differed for different types of tool's wear-resistant coating, but we are interested in the part of the graph with already steady state machining mode to obtain the correct results of the research. Based on the analysis of this graph's part, it can be seen that the temperature in the cutting zone for the hard alloy metal cutting insert reaches the following value:

- without applied wear-resistant coating - about $960^{\circ} \mathrm{C}$;

- for the TiAlN coating - about $810{ }^{\circ} \mathrm{C}$

- for the TiN coating - about $785^{\circ} \mathrm{C}$;

- for the TiC coating - about $725^{\circ} \mathrm{C}$;

- for the TiCN coating - about $690^{\circ} \mathrm{C}$.

Thus, the use of a wear-resistant coating allows to significantly reduce the temperature in the machining zone compared to the thermal parameters of the cutting process by the uncoated tool. However, the degree of temperature reduction mainly depends on the type of coating as follows:

- for the TiAlN coating, reduction of cutting temperature is about $15.6 \%$ compared to machining by uncoated tool;

- for the TiN coating, reduction of cutting temperature is about $18.2 \%$ compared to machining by uncoated tool;

- for the TiC coating, reduction of cutting temperature is about $24.5 \%$ compared to machining by uncoated tool;

- for the TiCN coating, reduction of cutting temperature is about $28.1 \%$ compared to machining by uncoated tool.

According to the obtained thermal parameters of the alloyed steel cutting process, it can be concluded that the use of the tool coating allows to reduce the temperature in the treatment zone 
by at least $15.6 \%$, while the use of the most effective type of coating for this hard-to-cut material, which according to the results of the simulation study has become titanium carbonitride, allows to reduce the temperature by as much as $28.1 \%$.

\subsection{Dependency of the chip thickness ratio and shear angle on the tool coating type}

Machinability indices for the difficult to cut materials used in cases when used different tool coatings have the characteristics such as chip thickness ratio and shear angle [20]. Most researchers do not pay due attention to these vital workability indicators needed to understand the effective cutting of these materials. Most of the researchers have not given due consideration to these vital machinability indices necessary for understanding of effective cutting of said materials.

As is known [21, 22], the chip thickness ratio $r$ depends on the shear angle $\beta$ and the rake angle $\alpha$ of the cutting tool:

$$
r=\frac{\sin \alpha}{\cos (\beta-\alpha)}
$$

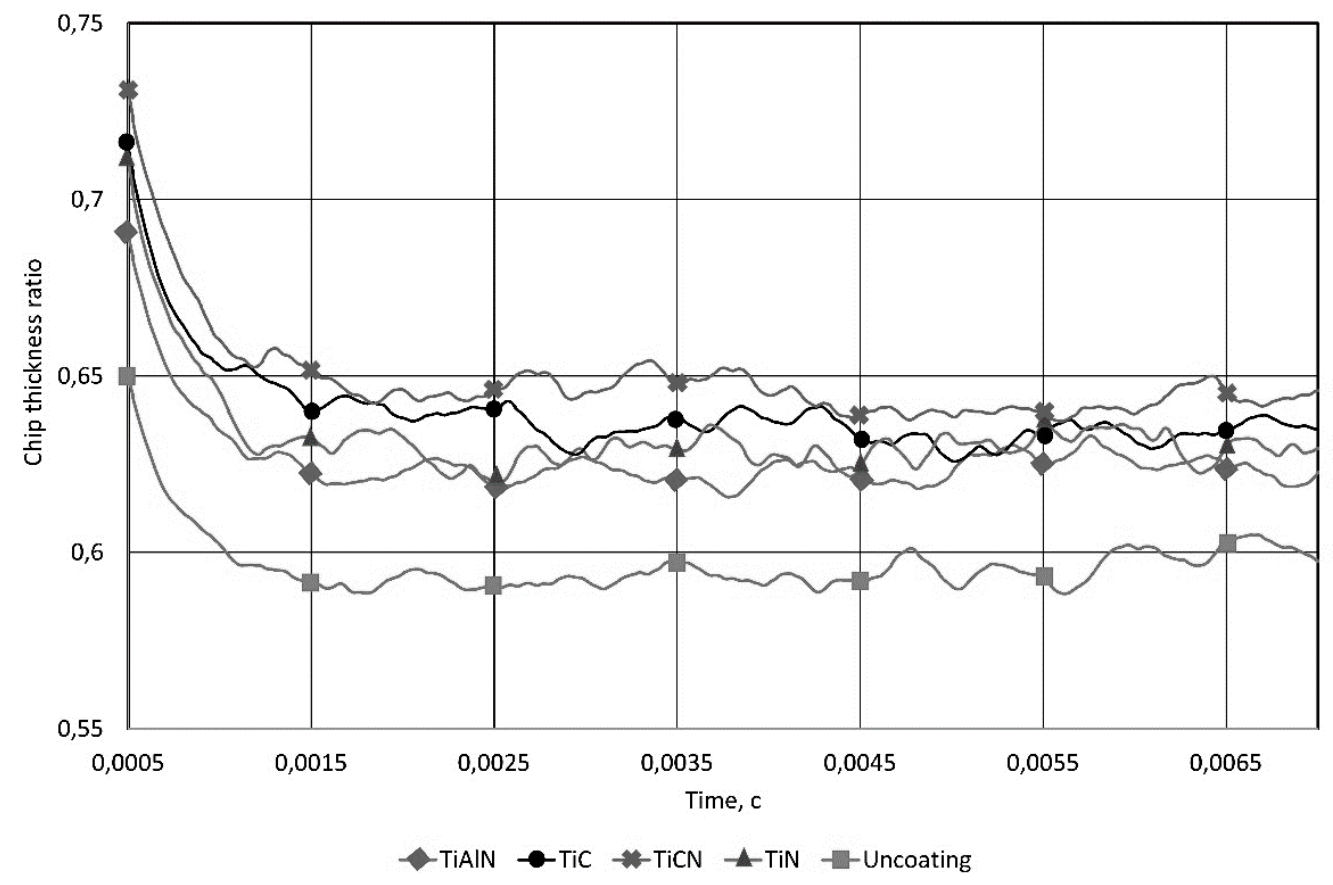

Fig. 3. Dependence of chip thickness ratio on wear-resistant tool coating type resulting from the simulation in Deform 2D

Based on a simulation study, a change in chip thickness ratio was analyzed depending on the type of wear-resistant tool coating used in alloyed steel AISI 4340 machining (Fig.3). According to the obtained results, the chip thickness ratio takes on the following values:

- without applied wear-resistant coating - about 0.59 ;

- for the TiAlN coating - about 0.62 ;

- for the TiN coating - about 0.63 ;

- for the TiC coating - about 0.65 ;

- for the TiCN coating - about 0.66 .

After evaluating these results, it can be argued that the chip thickness ratio depends, albeit slightly, on the type and presence of a wear-resistant coating. The obtained coefficients increase compared to the chip thickness ratio when cutting with an uncoated tool in such percentages 
- for the TiAlN coating, increase in chip thickness ratio is about $4.2 \%$ compared to machining by uncoated tool;

- for the TiN coating, increase in chip thickness ratio is about $6 \%$ compared to machining by uncoated tool;

- for the TiC coating, increase in chip thickness ratio is about $7.7 \%$ compared to machining by uncoated tool;

- for the TiCN coating, increase in chip thickness ratio is about $9.5 \%$ compared to machining by uncoated tool;

Comparing the obtained graphical relationships and the average values of the chip thickness ratio, we conclude that the presence of a wear-resistant coating allows to reduce the chip thickness factor by not less than $4.2 \%$. However, the type of coating has no significant effect on this coefficient, since the obtained average values of coefficients decrease according to the tested coatings with a difference of about 1.6-1.8\%.

Equally important characteristic of machining quality is shear angle when cutting hard-tocut materials by the tools with different wear-resistant coatings. The amount of shear angle can be defined in Deform 2D as a built-in function. This angle is theoretically determined by the formula [22]:

$$
\beta=\arctan \left(\frac{r \cdot \cos \alpha}{1-r \cdot \sin \alpha}\right)
$$

where $r$ is the chip thickness ratio; $\alpha$ is the rake angle of the cutting face.

A graphical interpretation of shear angle simulation results when cutting alloy steel AISI 4340 using tools with different wear-resistant coatings is shown in Fig. 4.

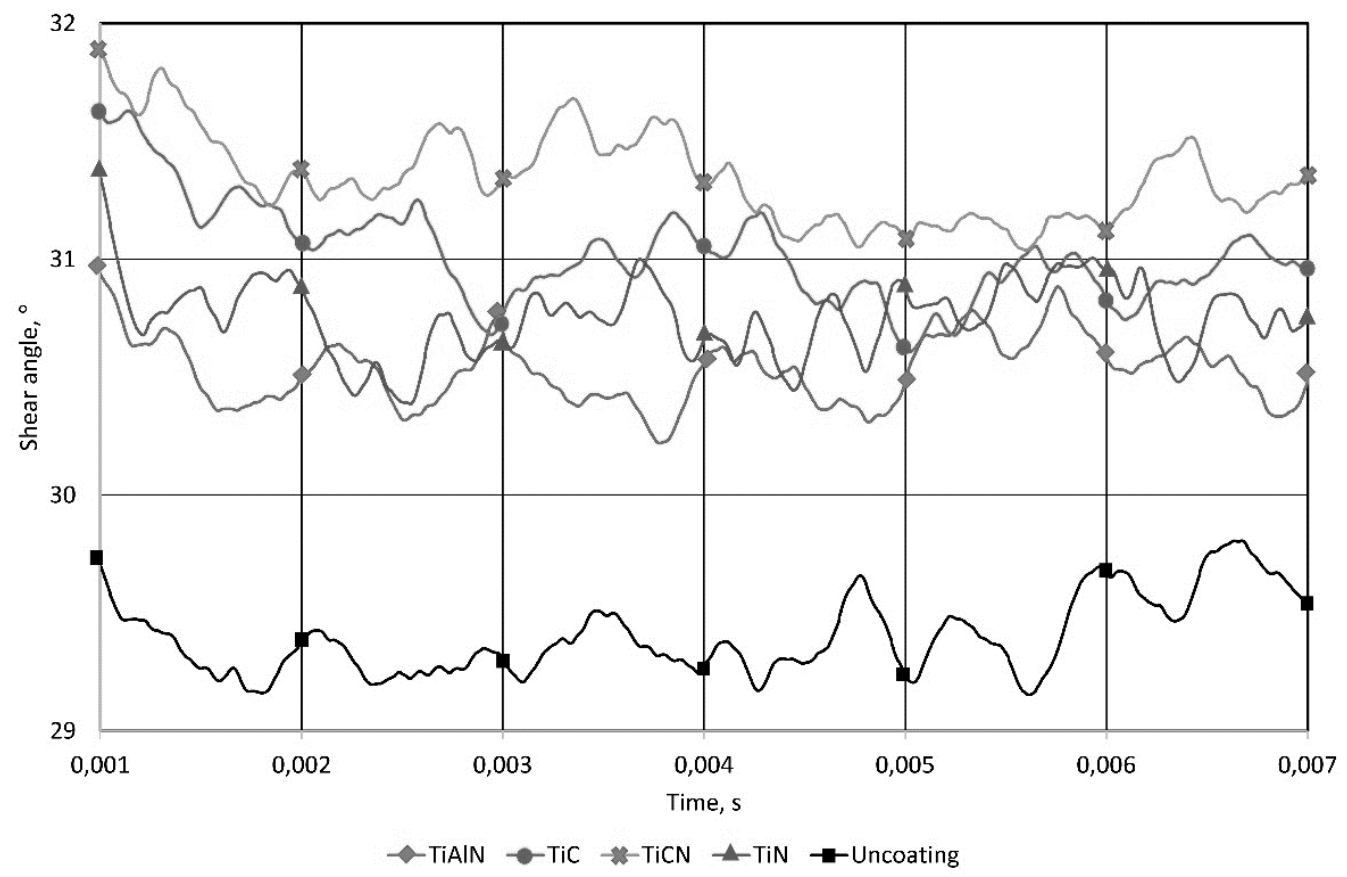

Fig. 4. Dependence of shear angle on wear-resistant tool coating type resulting from the simulation in Deform $2 \mathrm{D}$

For further consideration and analysis of the data received, we are interested in the results obtained, which correspond only to stable machining modes. Simulated in Deform 2D shear angle values when using wear-resistant coatings are following: 
- for the TiAlN coating - about 29,3;

- for the TiN coating - about $30,3^{\circ}$;

- for the TiC coating - about $30,8^{\circ}$;

- for the TiCN coating - about $31,3^{\circ}$.

\subsection{Dependency of the total cutting force on the tool coating type}

It is known [23] that the cutting force $P$ is a function of the area of the chips cross-section and defined as:

$$
P=\frac{S \cdot \tau}{r}
$$

where $S$ is the area of the chip cross section $\left(\mathrm{mm}^{2}\right) ; r$ is the chip thickness ratio; $\tau$ is the Ultimate Shear Strength of the workpiece material, MPa.

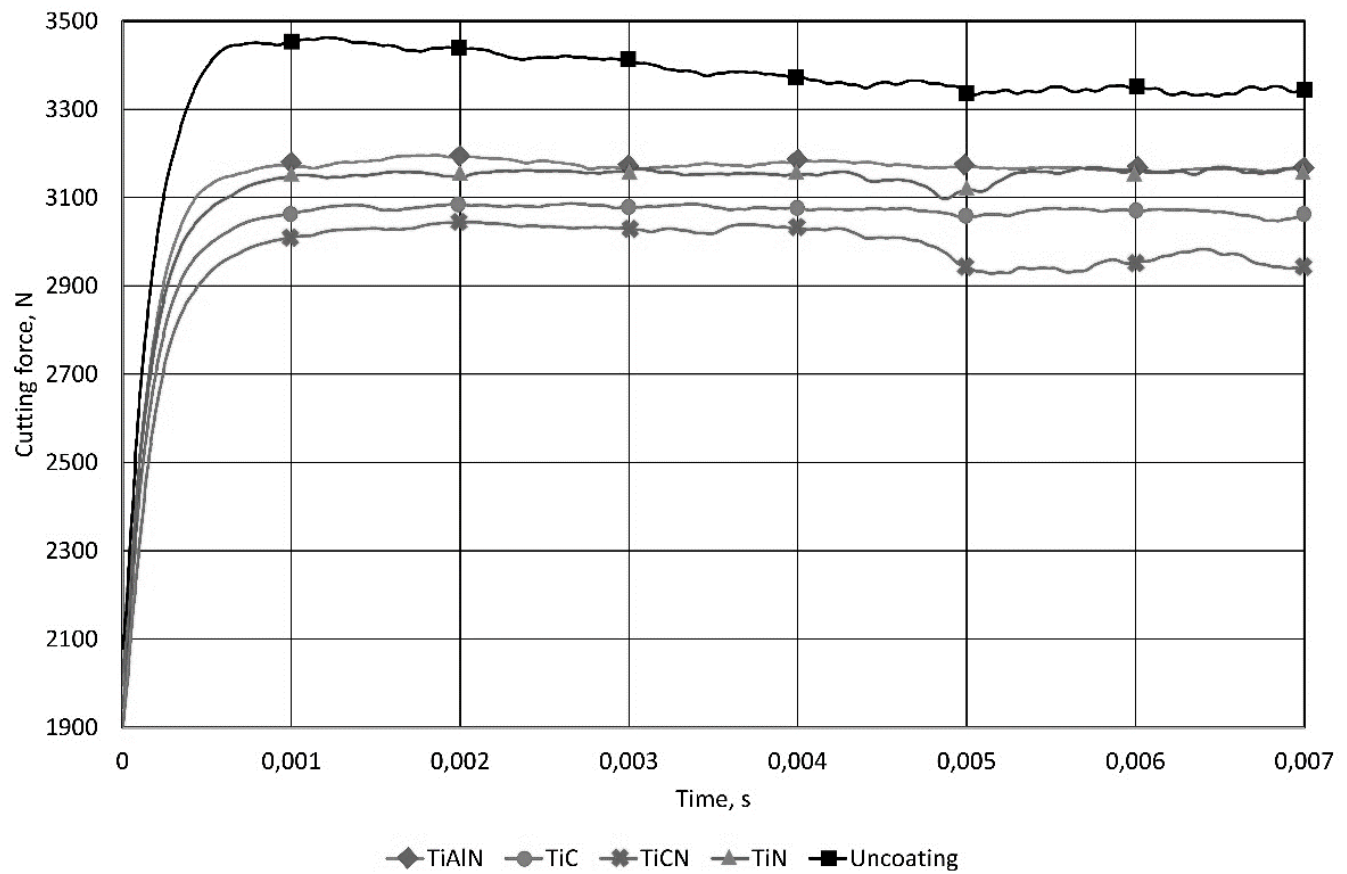

Fig. 5. Dependence of total cutting load on tool coating type resulting from the simulation in Deform 2D

According to the graph of results (Fig.5), it can be concluded that the increase in the total load starts already during the cut-in into the workpiece, but it is appropriate to use the values obtained during the stable machining process to get the correct analysis of the obtained values. These parameters vary depending on the type of wear-resistant coating applied to the hard alloy insert as follows:

- without applied wear-resistant coating - about $3390 \mathrm{~N}$;

- for the TiAlN coating - about $3160 \mathrm{~N}$;

- for the TiN coating - about $3145 \mathrm{~N}$;

- for the TiC coating - about $3085 \mathrm{~N}$;

- for the TiCN coating - about $2985 \mathrm{~N}$.

Thus, the use of a wear-resistant coating makes it possible to reduce the total cutting forces, which in turn depend on the different type of tool coating, in such percentages: 
- for the TiAlN coating, reduction of cutting load is about $6.8 \%$ compared to machining by uncoated tool;

- for the TiN coating, reduction of cutting load is about $7.2 \%$ compared to machining by uncoated tool;

- for the TiC coating, reduction of cutting load is about $9.0 \%$ compared to machining by uncoated tool;

- for the TiCN coating, reduction of cutting load is about $12.1 \%$ compared to machining by uncoated tool;

Therefore, it can be concluded that the application of the wear-resistant coating reduces the total cutting force during machining by at least $6.8 \%$. In addition, it is worth noting that when applying wear-resistant coatings based on titanium aluminum nitride and titanium nitride, the load decreases with a difference of $0.4 \%$. It may be permissible error at a certain stage of the study, so it can be concluded that these two types of coatings reduce the total cutting force with the same effect. Also, according to the analysis of the results, it is seen that most intensively reduces the total cutting loading during the use of a wear resistant type carbide-based coating, which means that for the selected material to be treated, this tool coating is the best among the options considered.

\subsection{Dependency of the tool wear rate on the coating type}

Obviously, the main advantage of using different coatings is the wear resistance of the cutting tool increasing. The simulation of the cutting-edge wear depends on the selection of the tool wear calculation model. The Usui and Archard criteria are used in Deform 2D (Fig. 6)

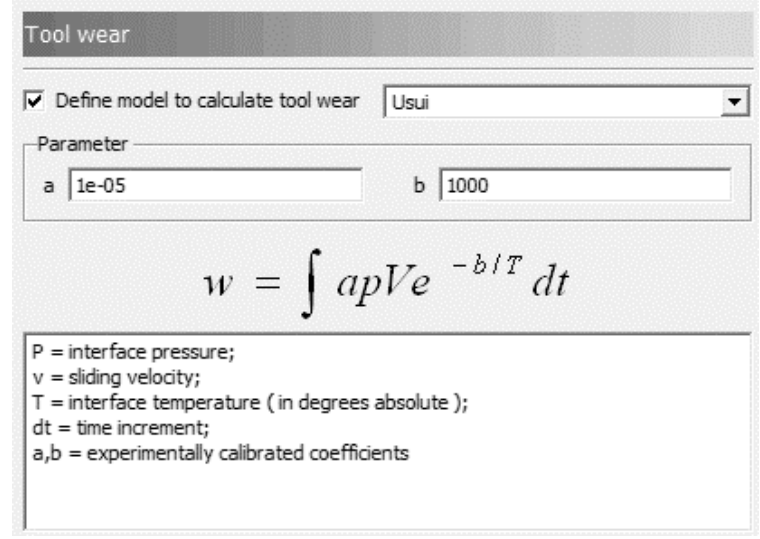

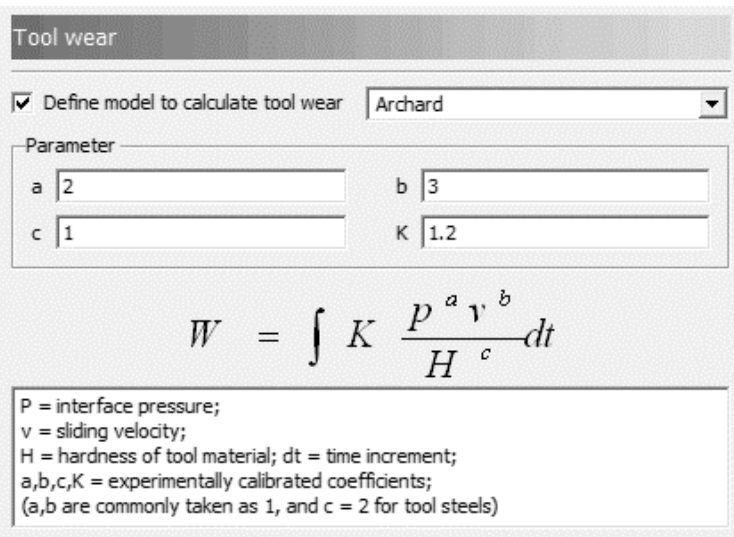

Fig. 6. Options of the choice of model to calculate tool wear in Deform 2D

Such important elements as interface pressure, cutting temperature, physical and mechanical characteristics of coating materials and workpiece, chip sliding velocity allow to simulate wear rate relative to models shown in Fig. 6. 

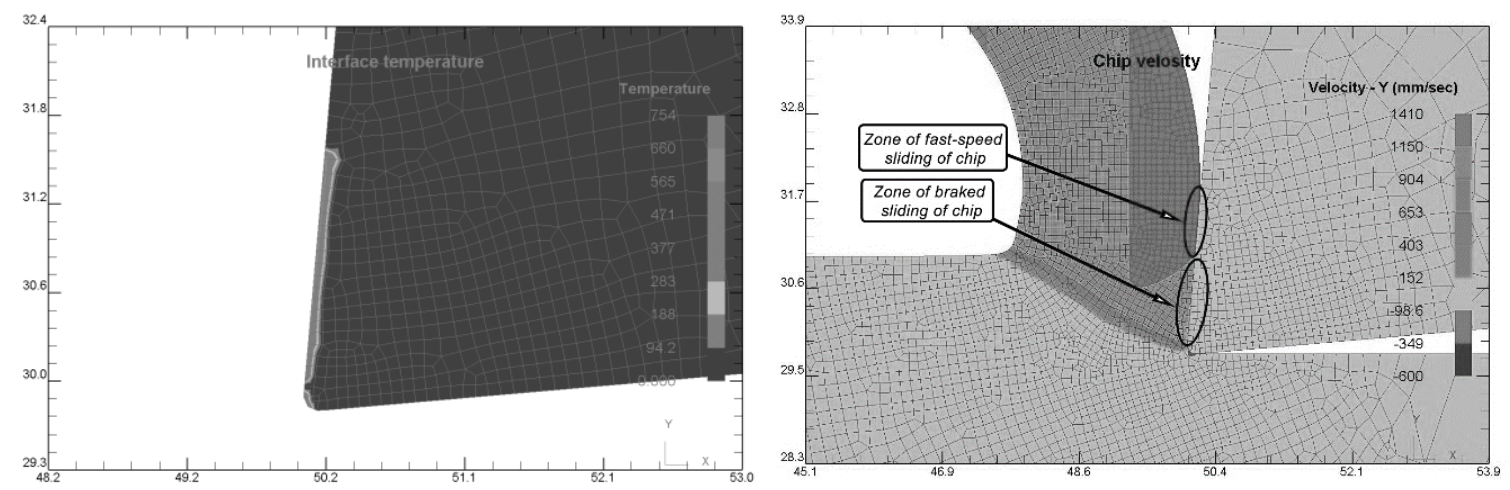

Fig. 7. Tool's interface temperature (a) and velocity of chip sliding along rake face (b) diagrams resulting from the simulation in Deform 2D

As can be seen from the analysis (Fig.7 (a)), the highest temperature (in a given case - $754^{\circ}$ C) does not occur at the top of the cutting edge, but where the chip sliding velocity along to the rake face is highest. In addition, the friction load is affected by the value of the chip specific pressure on the tool. The results of this simulation are shown in Fig. 8 (a). Therefore, the maximum tool wear rate is modeled at the point shown in Fig. 8 (b).

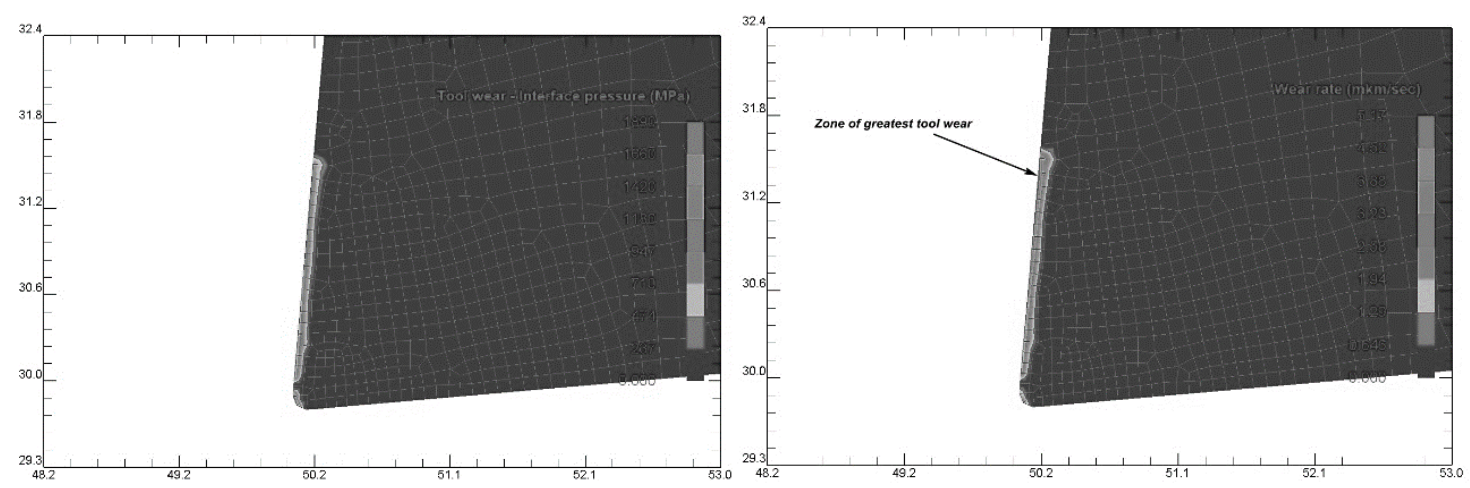

Fig. 8. Interface pressure diagram (a) and zone for tool wear rate simulation (b).

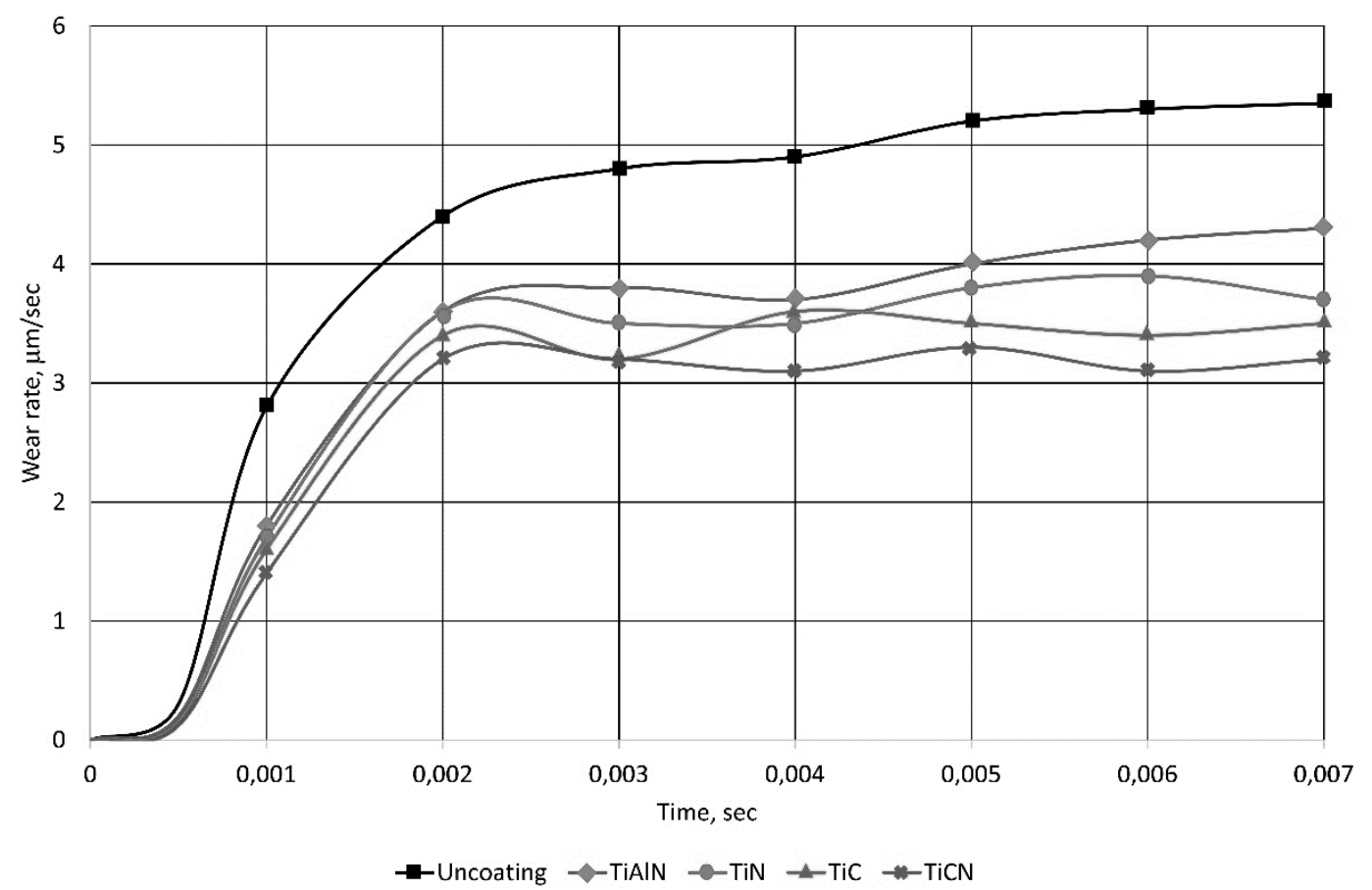

Fig. 9. Dependence of tool wear rate on coating type resulting from the simulation in Deform 2D 
The results of the simulation of the wear rate (Fig.9) of the hard insert during the cutting of the alloyed steel AISI 4340 by the tool with the different wear-resistant coatings used are as follows:

- without applied wear-resistant coating - about $5.3 \mu \mathrm{m} / \mathrm{sec}$;

- for the TiAlN coating - about $4.1 \mu \mathrm{m} / \mathrm{sec}$;

- for the TiN coating - about $3.9 \mu \mathrm{m} / \mathrm{sec}$;

- for the TiC coating - about $3.4 \mu \mathrm{m} / \mathrm{sec}$;

- for the TiCN coating - about $3.1 \mu \mathrm{m} / \mathrm{sec}$.

Thus, it can be concluded that there is an obvious advantage of coated tools over an uncoated tool to provide high wear resistance to the cutting insert, namely:

- for the TiAlN coating, reduction of wear rate is about $23 \%$ compared to machining by uncoated tool;

- for the TiN coating, reduction of wear rate is about $27 \%$ compared to machining by uncoated tool;

- for the TiC coating, reduction of wear rate is about $36 \%$ compared to machining by uncoated tool;

- for the TiCN coating, reduction of wear rate is about $42 \%$ compared to machining by uncoated tool.

\section{CONCLUSION}

Analysis of the simulation results of alloyed steel cutting by the tool with different coatings allows to draw the following conclusions

1. The greatest influence on the thermodynamic and stress-deformed state is the parameter of friction coefficient of the applied wear-resistant tool coating. This is particularly evident for thermal processes during cutting. For example, from the obtained temperature parameters of the alloyed steel cutting process, it can be concluded that the use of the tool coating allows to reduce the temperature in the treatment zone by at least $15-16 \%$ (TiAlN). When using the most effective type of coating ( $\mathrm{TiCN}$ ) the temperature can be reduced by about $28 \%$.

2. Power parameters of the process of cutting hard-to-cut materials depend significantly on the chip thickness ratio. Use of a wear-resistant coating allows to reduce the chip thickness factor by not less than $4.2 \%$. However, the type of coating has no significant effect on this coefficient, since the obtained average values of coefficients decrease according to the tested coatings with a difference of about 1.6-1.8\%. However, it can be concluded that the application of the wear-resistant coating reduces the total cutting force during machining by at least $6.8 \%$. In addition, it is worth noting that when applying wear-resistant coatings based on titanium aluminum nitride and titanium nitride, the load decreases with a difference of $0.4 \%$. It may be permissible error at a certain stage of the study, so it can be concluded that these two types of coatings reduce the total cutting force with the same effect. Also, according to the analysis of the results, it can be seen that the overall cutting load is most intensively reduced during use of the carbide-containing types of wear coating ( $\mathrm{TiC}, \mathrm{TiCN})$, which means that for the selected material to be treated, this tool coatings are the best of the embodiments discussed.

3. Certainly, the main advantage of using different coatings is the wear resistance of the cutting tool increasing. Such important elements such as interface pressure, cutting temperature, physical and mechanical characteristics of coating materials and workpiece, chip sliding 
velocity along rake face of the tool allow to simulate wear rate. As can be seen from the simulation results analysis, the highest temperature does not occur at the top of the cutting blade, but where the chip sliding velocity relative to the rake face of tool is highest. In addition, the friction load is affected by the value of the chip specific pressure on the tool. Therefore, the tool wear rate is modeled at this zone. The use of wear-resistant coatings reduces the wear rate of the cutting insert when machining the alloyed steel from $23 \%$ (TiAlN) to $42 \%$ (TiCN).

4. Cutting simulations using 2D/3D FEM software (such as DEFORM, ABAQUS, LSDyna, or AdvantEdge) can significantly accelerate and reduce the cost of analyzing the use of new wear-resistant coatings for different tool materials. It is evident that additional experimental research is required to more adequately describe the cutting process. However, their labor intensity and quantity can be significantly reduced by preliminary modelling. In addition, simulation results provide a large amount of cutting information (stress, strain, temperature, residual stress, etc.) that is very difficult (or impossible) to obtain from experimental studies.

\section{REFERENCES}

[1] Kishawy, H.A., Hosseini. "Machining Difficult-to-Cut Materials. Basic Principles and Challenges", Verlag: Springer International Publishing, Berlin, Germany, 2019. DOI:10.1007/978-3-319-95966-5

[2] Wojciechowski, S., Królczyk, G. M, Andradosław, Maruda, A. W. "Advances in Hardto-Cut Materials: Manufacturing, Properties, Process Mechanics and Evaluation of Surface Integrity", Printed Edition of the Special Issue Published in Materials, MDPI, Basel, Switzerland, 2020. DOI:10.3390/books978-3-03928-355-2

[3] Davim, J. P. "Machining of Hard Materials", Springer-Verlag, London, England, 2011. DOI:10.1007/978-1-84996-450-0

[4] Grzesik, W. "Advanced Machining Processes of Metallic Materials: Theory, Modelling and Applications”, Springer, London, England, 2017. DOI:10.1016/B978-0-08-0445342.X5001-2

[5] Mostaghimi, J., Chandra, S., Ghafouri-Azar, R., Dolatabadi, A. "Modeling thermal spray coating processes: a powerful tool in design and optimization", Surface and Coatings Technology 163 - 164, pp. 1 - 11, 2003. DOI:10.1016/S0257-8972(02)00686-2

[6] Bouzakis, K.-D., Michailidis, N., Skordarisa, G., Bouzakis, E., Biermann, D., M'Saoubi, R. "Cutting with coated tools: Coating technologies, characterization methods and performance optimization", CIRP Annals 61 (2), pp. 703 - 723, 2012. DOI: 10.1016/j.cirp.2012.05.006.

[7] Klocke, F., Krieg T. "Coated Tools for Metal Cutting - Features and Applications”, CIRP Annals 48 (2), pp. 515 - 525, 1999. DOI: 10.1016/S0007-8506(07)63231-4

[8] Kong, X., Yang, L., Zhang, H. "Cutting performance and coated tool wear mechanisms in laser-assisted milling K24 nickel-based superalloy", International Journal of Advanced Manufacturing Technology 77, pp. 2151 - 2163, 2015. DOI: 10.1007/s00170-014-66069

[9] Binder, M., Klocke, F., Lung, D. "Tool wear simulation of complex shaped coated cutting tools", Wears 330 - 331, pp. 600 - 607, 2015. DOI: 10.1016/j.wear.2015.01.015

[10] Yung-Chang Yen, Söhner, J., Lilly, B., Altana, T. "Estimation of tool wear in orthogonal cutting using the finite element analysis“, Journal of Materials Processing Technology 146 (1), pp. 82 - 91, 2004. DOI: 10.1016/S0924-0136(03)00847-1 
[11] Kone, F., Czarnota, C., Haddag, B., Nouari, M. "Finite element modelling of the thermomechanical behavior of coatings under extreme contact loading in dry machining", Surface and Coatings Technology 205 (12), pp. 3559 - 3566, 2011. DOI:10.1016/j.surfcoat.2010.12.024

[12] Kondala, D., Srinivasdr, K. "Comparision of Dominant Features Identification for Tool Wear in Hard Turning of Inconel 718 by Using Vibration Analysis", Strojnícky časopis - Journal of Mechanical Engineering 69 (4), pp. 1 - 8, 2019. DOI: 10.2478/scjme-20190038

[13] Choudhury, A., Mondal, S. C., Sarkar, S. "Effect of lamination angle and thickness on analysis of composite plate under thermo mechanical loading", Strojnícky časopis Journal of Mechanical Engineering 67 (1), pp. 5 - 22, 2017. DOI: 10.1515/scjme-20170001

[14] Bošanský, M., Gondár, E., Švec, P., Toth, F., Protasov, R. A. "Study of Wear in Thin Coatings Applied to Convex-Concave Gearings". Lubricants 8 (56), pp 1 - 14, 2020. DOI: $10.3390 /$ lubricants 8050056

[15] Bošanský, M., Tóth, F., Gulan, L., Rusnák, J., Furstenzeller, A. "Scuffing Resistance of 16MnCr5 HCR TiAlCN-Coated Gears", In: Current Methods of Construction Design. Lecture Notes in Mechanical Engineering. Springer, Cham, Switzerland, pp. 445 - 452, 2020. DOI: $10.1007 / 978-3-030-33146-7 \_51$

[16] Écsi, L., Jerábek R., Élesztős P. "Study On The 'Compatiblity Assumption' Of Contemporary Multiplicative Plasicity Models", Strojnícky časopis - Journal of Mechanical Engineering 69 (2), pp. 15 - 26, 2019. DOI: 10.2478/scjme-2019-0015

[17] Stupnytskyy, V., Hrytsay, I. "Computer-Aided Conception for Planning and Researching of the Functional-Oriented Manufacturing Process", In: Advanced Manufacturing Processes. InterPartner-2019. Lecture Notes in Mechanical Engineering, Springer, Cham, Switzerland, pp. 309 - 322, 2020. DOI: 10.1007/978-3-030-40724-7_32

[18] Constantin, C., Croitoru, S. M., Constantin, G., Străjescu, E. "FEM tools for cutting process modelling and simulation", Scientific Bulletin, Series D: Mechanical Engineering 74 (4), pp. 149 - 162, 2012. Available at: https://www.researchgate.net/ publication/234885540_FEM_tools_for_cutting_process_modelling_and_simulation

[19] Yung-Chang Yena, Jörg S., Blaine, L., Taylan A. "Estimation of tool wear in orthogonal cutting using the finite element analysis", Journal of Materials Processing Technology 146 (1), pp. 82 - 91, 2004. DOI: 10.1016/S0924-0136(03)00847-1

[20] Thamizhmanii, S., Sulaiman, H. "Machinability Study Using Chip Thickness Ratio on Difficult to Cut Metals by CBN Cutting Tool", Key Engineering Materials s 504 - 506, pp. 1317 - 1322, 2012. DOI: 10.4028/www.scientific.net/kem.504-506.1317

[21] Hassan El-Hofy. "Fundamentals of Machining Processes: Conventional and Nonconventional Processes", Taylor \& Francis, Boca Raton, USA, 2014. DOI: $10.1201 / 978042944332$

[22] Klocke, F. "Manufacturing Processes 1. Cutting", RWTH, Springer-Verlag, BerlinHeidelberg, Germany, 2011. DOI:10.1007/978-3-642-11979-8.

[23] Hrytsay, I., Stupnytskyy, V., Topchii, V. "Improved Method of Gear Hobbing Computer Aided Simulation”. Archive of mechanical engineering 66 (4), pp. 475 - 494, 2019. DOI: 10.24425/ame.2019.131358. 